\title{
Recognising and addressing elder abuse in care homes:

\author{
views from residents and
}

managers

\author{
abstract
}

In 2004, the author carried out a

small scale study to find out the views of those living and working in private care homes in England about a range of issues connected to inspection, regulation and ways to better protect older people. This study reports on views from 19 managers and 19 residents about their understanding of abuse, their perceptions of the different forms of abuse and the possible action to

deal with offending care staff. Although there was some consensus about the seriousness of certain types of abuse and how managers would investigate the allegation, the findings indicate that mandatory training for registered care home owners and managers is necessary to clarify their responsibilities in relation to their actions and the reporting of certain offences to relevant agencies. Residents' views also need to be taken seriously if they are to voice their opinions about life in a care home.

$$
\begin{array}{r}
\text { key words } \\
\text { abuse } \\
\text { judgement } \\
\text { protection } \\
\text { policies } \\
\text { care homes } \\
\text { older people }
\end{array}
$$

\section{Sheila Furness \\ Lecturer, Department of Social Sciences and Humanities}

\section{Introduction}

Older people are abused, both within their own homes and in institutional settings (Baker, 1975; Eastman, 1984; Gilleard, 1994; Kingston \& Brammer, 1997; Commission for Health Improvement, 2000; House of Commons Health Select Committee, 2004). During 1997-1999, one quarter of telephone calls to a helpline, set up by the charity Action on Elder Abuse, related to abuse in hospitals, nursing and residential care homes (Bennett, Jenkins \& Asif, 2000). Although progress has been made in bringing this to the attention of policy makers, government, practitioners and the public there is still a need for this issue to be taken more seriously. It is very difficult to ascertain the prevalence of abuse. Different understandings about what constitutes abuse and views about the severity and seriousness of its varied forms complicate the reporting and management of the problem. This paper considers the views of managers and residents living in private care homes for older people about their understanding of abuse and the action that should be taken to deal with allegations of abuse. Their responses to case scenarios and the appropriate action that they would take to tackle the problem are examined. The final section considers the effectiveness of adult protection policies as an adequate means of safeguarding older people from abuse in care homes. A framework to guide registered care home managers to deal with allegations of abuse has been developed to aid their decision-making. 


\section{Context}

The Registered Homes Act 1984 was a key piece of legislation introduced to improve standards in care homes by providing tougher regulatory checks and controls of private and voluntary sector homes. Ongoing criticisms about the need to provide national guidance about minimum standards for care homes and independent, fairer and more consistent regulation led to the Care Standards Act (CSA) 2000 that established the regulatory system for care services in England. Section one of the CSA 2000 identified a nondepartmental public body, the National Care Standards Commission (NCSC) replaced one year later by the Commission for Social Care Inspection ( $\mathrm{CSCI})$, to be responsible for the registration and inspection of social care services. Section 23(1) of the CSA 2000 sets out the National Minimum Care Standards (NMS) for care homes for older people. The $\mathrm{CSCI}$ assesses the quality of services against these standards and statutory regulations. An overarching aim is to ensure the protection of service users and improve the quality of service received. A key target of 2002-3 was to investigate the causes of 'adverse incidents' to aid risk assessment and help protect vulnerable people (NCSC, 2003: 34).

Regulation 37 of the Care Homes Regulations (CHR) 2001 requires the registered person to notify the Commission of death; serious injury; theft, burglary or accident without delay. It indicates that this applies to 'any event in the care home which adversely affects the well-being or safety of any service user' and 'any allegation of misconduct by the registered person or any person who works at the care home' (CHR, 2001: 1). The guidance is very clear that any allegation of abuse or suspicion of abuse towards a service user should be reported to the Commission. Taylor and Dodd (2003) interviewed 150 staff working with different adult client groups about their understanding and reporting of abuse. Their findings indicate that the beliefs and knowledge of the worker can interfere with the reporting of abuse. Although training can positively affect staff awareness and attitudes towards abuse other ways need to be explored to overcome a worker's reluctance to report abuse.

In 2003, concerns about the prevalence and low reporting of institutional elder abuse in Iowa led to a survey of 409 nursing homes. The administrators and directors of nursing at these homes were asked a number of questions to determine any association between the reporting of abuse to state authorities and their knowledge of the law relating to elder abuse. Sixty-six per cent of respondents reported the allegation to the Iowa Department of Inspections and Appeals, $31 \%$ to the police, and $41 \%$ to the Iowa Department of Human Resources. In the American survey, reasons cited for nonreporting were: allegation was unfounded after internal investigation (19\%), told not to report by boss $(0.1 \%)$, previously reported abuse and regulatory body did nothing $(0.1 \%)$, reported abuse in past and it led to bad outcome $(0.5 \%)$, and reported abuse in the past and it was ruled out by the regulatory body $(0.2 \%)$. Respondents were also invited to add comments about their dealings with either the regulatory body or local authority. Their issues included a concern about the length of time taken to investigate a case, an obvious case being unfounded and a belief that the regulatory body would look for other deficiencies and penalise homes for reporting abuse (Daly \& Jogerst, 2005). There are evident barriers preventing the reporting of incidents of abuse.

The Department of Health (DoH) published its white paper Modernising Social Services - Promoting Independence, Improving Protection, Raising Standards as a sign of its commitment to the protection of vulnerable people ( $\mathrm{DoH}, 1998)$. In 2000, this was followed by the guidance No Secrets 
under Section 7 of the Local Authority Social Services Act 1970. This policy required social services, as the lead agency, to establish robust multi-agency procedures to respond to incidents of abuse (DoH, 2000b). Studies suggest that there have been very different responses and identified resources to match the requirement to establish formal mechanisms to deal with allegations of the abuse of vulnerable adults. Although most local authorities have set up an adult protection unit (APU) to lead and co-ordinate local adult protection strategies, there are wide variations in the approach adopted by different authorities in England (Mathew et al, 2002; Sumner, 2004).

Following the implementation of No Secrets there is now a requirement for all registered care homes to maintain up to date adult protection policies and for staff to have training in recognising and dealing with suspected abuse. These policies are checked as part of the annual inspections carried out by the Commission for Social Care Inspection (CSCI). Richardson, Kitchen and Livingston (2002) identified that there was inconsistency around the identification, reporting and management of elder abuse. A lack of familiarity with the policies on the management of abuse was one reason named for its persistence and that printed educational material was largely ineffective in aiding staff to deal with such cases.

Part VII CSA 2000 requires the

Department of Health to maintain a protection of vulnerable adults register (POVA). Employers have a responsibility to check this register when employing a new member of staff as part of the Criminal Records Bureau (CRB) disclosure checks. There is also a responsibility to refer any member of staff who they suspect of or has been found guilty of misconduct that harmed or placed service users at risk. Stevens and Manthorpe (2005) interrogated the first 100 referrals to POVA to identify commonalities amongst the referrers, types of case and outcomes. Twenty-one cases had been reported to the local council with social services responsibility (CSSR), 12 cases had been reported to CSCI, 10 cases had been reported to the adult protection unit (APU) and 40 cases to the police. Stevens and Manthorpe suggest that employers would benefit from more guidance about the role of APU and CSCI in relation to making referrals to POVA.

\section{The study}

In 2004, interviews were carried out with 19 care home owners or managers and 19 residents living in registered private care homes in the North of England. The aim of the study was to find out their views about inspection, regulation and adult protection. This section of the article will examine some of their responses about their understanding of abuse and what action they thought should be taken to deal with hypothetical case examples. Cases only concerned possible abusive relationships between staff and residents. It was not within the scope of this study to consider other relationships. Managers were also asked about their adult protection policies and how these worked in practice.

\section{Methodology}

Initial contact (by letter) was made to the care home owner or manager to explain the purpose of the study. All homes targeted for inclusion were registered to accommodate older people. Specialist homes and small homes of less than four people were excluded. At the start of the project there were 47 care homes listed as registered care homes that met this criterion within the geographical area. The local authority 


\section{Table 1 Summary of legal developments affecting care homes}

1984 Registered Homes Act - regulation and inspection of private and voluntary homes

1990 NHS and Community Care Act - provisions of 1984 Act extended to local authority homes

1998 Modernising Social Services - protection as key priority

1998 Public Disclosure Act

2000 No Secrets - guidance on multi-agency policies on adult protection

2000 Care Standards Act - setting up of National Care Standards Commission responsible for registration and inspection of social care services; national minimum care standards for care homes for older people (S 23); codes of practice to be introduced for social care workers (S62); introduction of Protection of Vulnerable Adults register (POVA)

2001 Care Homes Regulations - staff training around abuse

2001 National Care Standards Commission merges with Social Services Inspectorate to become Commission for Social Care Inspection

2002 General Social Care Council codes of practice for social care workers

2005 Skills for Care (training body for social care workforce) introduces compulsory module on recognising and responding to abuse and neglect

managed three of these homes and the others were privately owned. Prospective participants were contacted by telephone to provide further information and invited to take part by consenting to be interviewed at the home. A small number of homes declined to take part on the grounds of 'work pressures'. In total 19 care homes participated in the study; all privately owned. Those who agreed to the interview were asked to identify any of their residents who could be approached to take part in the study. Nineteen residents were recruited (one from each of the care homes). Residents were then asked to give their verbal and written consent to the interview. All interviews were carried out by the same independent interviewer and were tape recorded and transcribed to aid analysis.

Both managers and residents were asked a number of questions as part of the interview. Six case scenarios about possible abuse were described towards the end of the interview as it was thought that this could be a potentially sensitive topic and could lead to disclosure about abuse (see appendix for part of the questionnaire used with the manager and resident at each home). Prior to setting up the study, the author and interviewer met with the local adult protection co-ordinator to inform her about the study and agree the course of action to be taken if the interviewer suspected or was informed about abuse. No disclosures occurred during any of the interviews. However, as a matter of good practice, it was very helpful for the interviewer to know a course of action to follow if presented with this ethical dilemma.

\section{Findings}

\section{Defining abuse}

Managers and residents were both asked to provide examples of unacceptable practices. Managers were asked about their understanding of abuse and their answers reflected the different forms of abuse with the exception of sexual abuse. This omission may reflect ageist assumptions or the hidden nature of the abuse (Manthorpe, 2000; Parker, 2001). All managers answered this question but some gave more detailed responses than others: 16 identified physical abuse, 12 verbal abuse, 10 named financial 
and mental/psychological abuse. Smaller numbers provided other examples: seven identified the restriction of rights, six neglect, five a lack of choice, three institutional or environmental factors, two cited medication wrongly or not administered and one punishment.

Initially residents were asked to provide examples of unacceptable practices in a home before being presented with different case scenarios. The question was qualified to make it clear that these were general and not specific to their home. Six of the 19 residents each identified one of the following examples: inadequate numbers of staff, mistreatment, rough handling, poor cleanliness of the home, 'too much bossing around that makes the place like an institution rather than your own home' and inferior meals. Thirteen of the 19 did not provide any examples.

Managers were asked a second question about whether they had ever witnessed any type of abuse in their working lives. 17 respondents (90\%) indicated that they had either first or second hand knowledge of abuse occurring in previous or present care settings. In many ways it was reassuring managers were able to be honest enough to disclose this fact but of concern that this supports other studies that have reported high levels of abuse within institutional settings (Pillemer \& Moore, 1989; DoH, 2005). Examples of known abuse were very wide ranging and included: rough handling (5), speaking inappropriately or sharply to a resident (5), residents being left on the commode/ toilet (3), physical abuse (2), theft (1), force feeding (1), lack of choice (1), lack of respect for dignity and privacy (1), misuse of medication (1), male resident hitting his wife who had dementia (1), resident sexually harassing another resident (1), sexual harassment between members of staff (1), member of staff drunk on duty (1), staff assaulted by resident (1) and difficulties when staff retaliated against a resident who was physically or verbally attacking a member of staff (1).

\section{Dealing with abuse}

Managers were presented with six different case scenarios and were asked to rate the severity of a particular type of abuse as a percentage. As a point of comparison, residents were presented with similar situations with the exception of the first example of physical abuse.

Managers were asked a second question to explain the procedures they would follow to deal with the abuse (see Table 2). They were also asked to identify factors that informed

\section{Table 2 Action by manager to deal with cases of abuse}

\begin{tabular}{|c|c|c|c|c|}
\hline Action & $\begin{array}{l}\text { Physical } \\
\text { abuse }\end{array}$ & Theft & $\begin{array}{l}\text { Rough } \\
\text { handling }\end{array}$ & $\begin{array}{l}\text { Ridiculing } \\
\text { resident }\end{array}$ \\
\hline Gross misconduct & $18(95 \%)$ & $17(90 \%)$ & & $1(5 \%)$ \\
\hline Verbal warning & & & $14(74 \%)$ & $7(27 \%)$ \\
\hline Advice and guidance & & & & $10(53 \%)$ \\
\hline Retraining & & & $10(53 \%)$ & $3(16 \%)$ \\
\hline Monitoring & & & $5(26 \%)$ & $2(11 \%)$ \\
\hline Police & $4(21 \%)$ & $6(32 \%)$ & & \\
\hline $\mathrm{CSCl}$ & $2(11 \%)$ & $4(21 \%)$ & & \\
\hline APU/SS & $1(5 \%)$ & $2(11 \%)$ & & \\
\hline POVA & $1(5 \%)$ & $2(11 \%)$ & & \\
\hline
\end{tabular}


their judgement and decision-making in responding to suspicions and allegations of abuse.

\section{Physical abuse}

The first example given (to the managers only) was of a member of staff slapping a resident. Unanimously all managers rated this as extremely serious and scored it as one of the most serious forms of abuse at $100 \%$.

Respondent answers indicated that they would deal with the member of staff in similar ways. This entailed interviewing the member of staff, taking written statements, a suspension of the member of staff pending a full investigation (in one case on no pay and in another on full pay). The member of staff would be instantly dismissed if the allegation was found to be proven. However, there were variations in the reporting of this offence: 18 saw this as gross misconduct and that it was a dismissible offence, four would report this to the police as a criminal offence and two would report this to the CSCI. Only one would report this to their local APU and one would refer the staff member to POVA for inclusion on the register.

\section{Theft}

The second example given was of a member of staff stealing money from a resident's purse. Again managers viewed this as extremely serious and 17 (90\%) indicated that it would lead to dismissal. One manager qualified this by saying that if it was the first time then a warning would be given but if it happened again the staff member would be dismissed. In their answers about what should happen to the member of staff then six would report this to the police, four would report this to CSCI, two would report to APU and two would refer to POVA.

Seven residents viewed this as 'very serious' and gave it a score of $100 \%$. When asked about the action they would take 16 indicated that they would report this to the manager or owner and two would challenge the member of staff. In terms of action to deal with the offence, 11 thought that the member of staff should be dismissed, three thought that any action was at the manager's discretion, two thought the member of staff should be reprimanded and one thought the staff member should receive either a reprimand or dismissal.

\section{Rough handling}

The example given was of a member of staff roughly pulling a resident out of a chair. Five managers indicated that they had previously had to address the poor handling techniques of their staff. Fourteen managers would reprimand and give a verbal warning to their staff, 10 also indicated that they would offer retraining and five would monitor the staff member. Although managers were largely in agreement about how they would deal with this situation their views about the seriousness of the action ranged from one to seven. Their judgement about severity was dependent on whether this was a first or second occurrence, whether the member of staff was under any personal stress and whether this was perceived as accidental. Although the effect was the same, the culpability differed. Some managers expressed this by their willingness to show the staff member the correct procedures and offer retraining. Respondents were able to articulate a process from giving a verbal warning with retraining followed by observation and monitoring of the worker's manual handling skills. None mentioned reporting this to external agencies.

Residents views varied as six clearly sympathised with the difficulties that staff faced, particularly when caring for residents who had dementia. Eight would report this to the manager and four would not tell anyone. A stark example of powerlessness was stated by one resident who said 'the man who holds the gun is always boss so I'd say nothing'. Another resident said, 'I can't say. I don't want 
to cause any bother'. Three said that they would challenge the member of staff directly and two did not know what action they would take. When asked about the possible consequences of reporting this four thought that the member of staff should be reprimanded and three were in favour of dismissal.

The difference in views seems to indicate that some residents would wish the manager to deal with this more seriously. However, there was also support from the residents about the stress associated with the job and dealing with 'difficult' residents. Worryingly about a quarter of the residents remained silent.

Ridiculing a resident who had dementia Managers rated this as extremely serious and that this was a 'cruel' act. Two managers struggled with identifying the right course of action, as they had never experienced this. One manager confirmed that this had recently happened and the member of staff had been verbally warned. This had happened again and the care worker had been given a written warning. The worker gave her notice and left. Ten managers would give advice and guidance to the member of staff and, in some homes, seven would also issue verbal warnings. One manager said that this would be instant dismissal and three managers would require the person to attend relevant training.

Most residents thought that this was serious and some could not imagine it happening at all. In terms of dealing with this, five would report this, five did not believe that it would happen, four would say nothing, four were not sure what they would do and one would reprimand the member of staff.

Other concerns

Managers were asked to identify any other examples of abuse that had not already been covered in the case studies. Fourteen managers identified situations of neglect, some making a distinction between wilful neglect by deliberately ignoring calls for help and unintentional neglect such as staff forgetting to administer medication to a resident or not checking that a resident had administered any medication if the resident self-medicated, failure to carry out simple nursing procedures like turning patients regularly when restricted to bed. Three managers expressed concerns about the failure to feed residents. One manager described an occasion when a resident had been admitted to hospital and was contacted two days later by the hospital staff to ask for details of the amount of help the person needed with daily living tasks. This resident was totally dependent on staff and needed help with feeding. The manager was left alarmed and unsure whether the resident had eaten during this two-day period. Other examples given were when food was taken away too quickly or a resident had been forcefed by staff.

One manager stressed the importance of treating residents with respect and that it was important to find a balance from 'having a laugh' with a resident but making sure that this did not offend the person and that jokes were 'with' and not at the expense of others. Two managers thought that it was important for staff not to make assumptions about choice of dress, drinks etc and consequently denying resident choice and decision-making.

One manager gave an example from her previous employment where a resident had been wheeled from the bedroom to the bathroom wearing no clothes. Other examples included leaving the toilet door open and staff chatting whilst waiting outside for the resident to finish using the toilet. Five managers gave examples where staff had demeaned residents by either their tone of voice, by arguing or shouting at residents and acting in a patronising manner. 
In contrast, 11 residents could not identify any other examples of matters that would concern them. This was qualified with statements such as 'they're all nice in here' and 'I can't say a right lot because it's not really bad'.

\section{Seeking advice and support}

Respondents were asked where they would turn for advice and support if they had to investigate any allegations of abuse (see Table 3). Some managers named up to three different sources of support in their answers. The results are of interest in that 13 managers indicated that they would contact their inspector or CSCI. One respondent qualified this 'as a last resort' and another was unsure what support would be given by CSCI. Six managers would contact APU (4) or social services (2). A number of respondents belonged to larger companies and, as a consequence, five would contact their group home manager and two would contact their human resources department or head office. Three managers would consult with colleagues and deal with this as an internal matter. Two managers would consult the proprietor of the home. Two managers would

\section{Table 3 Sources of advice and support for managers}

\begin{tabular}{l|l}
\multicolumn{1}{l}{$\begin{array}{l}\text { Agency } \\
\text { CSCl }\end{array}$} & $\begin{array}{l}\text { Numbers of } \\
\text { managers }\end{array}$ \\
\hline APU/SS & $13(68 \%)$ \\
\hline Group home manager & $5 / 2(32 \%)$ \\
\hline Colleagues & $3(16 \%)$ \\
\hline $\begin{array}{l}\text { HR department I } \\
\text { head office }\end{array}$ & $2(11 \%)$ \\
\hline Owner & $2(11 \%)$ \\
\hline Legal advisor & $2(11 \%)$ \\
\hline GP & $1(5 \%)$ \\
\hline Police & $1(5 \%)$ \\
\hline
\end{tabular}

contact the home's legal advisor. One manager would contact the home's GP and one manager would contact the police.

Although, it is encouraging that two thirds of respondents would contact their regulatory authority for advice and guidance, more could be done to promote the use of outside agencies as a source of support and expertise.

Residents were also asked to indicate whether they would relay any concerns to the manager, owner, staff, relatives or friends, other residents or an inspector. The majority of residents - 15 (78\%) - said that they would speak to the manager of the home and nine believed that their views would be listened to and taken seriously. Twelve would also speak to their relatives or close friends and seek their advice about the matter. Seven residents would speak to other staff at the home. Only five would speak to an inspector and qualified this with the following statements 'possibly', 'only if this was serious', 'only if asked' and 'if the incident was recent and was remembered at the time of the inspection visit'. Residents indicated that they would only report concerns to inspectors if the abuse was repeated and was really serious. This implies that residents are more likely to report any concerns to those who they have more regular contact with and trust.

\section{Adult protection policies}

In line with No Secrets all of the homes had their local authority adult protection policy and 13 managers were able to provide some explanation of the policy. Two managers recognised that the policy only gave staff some basic understanding and it was important for staff to attend training. Some managers reported that staff were given a copy of the policy and then asked questions to test their understanding of the causes and indicators of abuse. Staff were given this information during their induction period 
and then this was reinforced as part of their NVQ training. Five managers could not explain the policy and added comments like 'you've caught me on the hop there, without looking it up I'll admit I can't tell you', 'well I've not had to use it so I don't know', 'at the moment I don't think anybody's hardly read them. We've got them because we've got to have them'. Having a policy is only a starting point and clearly training needs to be carried out with managers to better equip them to translate the policy into practice. For some managers, the requirement to have different policies created additional pressures and as a consequence this had become a paperwork exercise rather than an identified and understood course of action.

\section{Ways forward}

\section{Listening to residents}

Greater attention needs to be paid to seeking 'service user' feedback as part of the revised CSCI inspection methodology. This small study has shown that only five residents (26\%) would raise serious concerns with an inspector. CSI propose to reduce the number of annual inspection visits to those homes deemed to be providing satisfactory levels of care. Instead, if inspections were more frequent then residents would come to know and trust their inspectors. Although 15 residents (78\%) would discuss any concerns with the manager of the home only $50 \%$ of the residents believed that their views would be taken seriously by the manager. This is an important point that needs to be considered in relation to adult protection and quality assurance procedures. When asked what action they would take in relation to each of the case scenarios, residents were selective in that the majority would report theft but one quarter would not report rough handling and over half would not report an instance of staff ridiculing a resident who had dementia. Care homes have a responsibility to ensure that residents understand their rights and are given opportunities to express their views and any concerns in a safe environment. They also need to have confidence that the appropriate action will be taken by staff.

Care homes will have to submit an annual quality assurance assessment that includes how they have addressed and taken into account service user views (DoH, 2005). It is likely that resident and manager priorities differ in relation to a range of issues affecting their daily lives. Residents viewed inadequate staffing and poor cleanliness of the home as examples of unacceptable practices. None of the managers identified either of these in their examples of abuse. Recruitment difficulties in care homes have been well documented and managing and retaining staff are a daily part of the manager's role (O'Kell, 2002). Residents who rely on staff for help with daily living tasks will experience staff shortages more acutely particularly if this becomes a regular and long term occurrence. Homes not only need to develop ways of providing greater opportunities for residents to comment on their experiences of living in the home but also show that they listen, value and respond to these views. Homes can develop a number of ways of demonstrating greater user and relative involvement, for example by setting up 'friends of the care home' groups, use of advocacy, survey and regular resident meetings.

\section{A framework to aid decision-making}

Managers were asked to identify the factors that would influence the course of action they would take to deal with an allegation of abuse. Their answers varied and it was clear that the course of action taken in relation to each situation would be dependent on a number of factors. One apparent factor was 
the lack of experience of the manager in having to deal with cases of abuse. Those who had not had to investigate abuse were less confident in their answers to this question. Although there is an expectation for registered managers to have relevant care experience and the qualifications to be deemed suitable to manage a care home, there is a need for additional training to enable managers to develop a clearer understanding of their responsibilities in relation to the reporting and investigation of cases of abuse.

No Secrets provides a framework to guide the practitioner to determine the appropriate intervention in cases of suspected abuse. Important factors that need to be considered include the 'vulnerability' of the individual, the nature and extent of the abuse, the length of time, the impact on the individual and the risk of repeated or increasingly serious harm to the person and others ( $\mathrm{DoH}$, 2000b: 2.18).

The manager is the key person who has the legal responsibility to deal with allegations of abuse. Managers need to be aware of the possible indicators of abuse and be alert and vigilant to respond to any 'cause for concern' resulting from unexplained or contradictory explanations for injuries, changes in resident behaviour and appearance, staff failure to carry out caring tasks and their attitude and relationships with others. The care manager may also receive an allegation of abuse from another party. At this stage, it is important that the manager acts quickly and treats the report seriously. Unfortunately there is evidence that many serious complaints have not been adequately investigated because of disbelief or dismissal by the relevant authorities (Burgner, Russell \& Whitehead, 1998; Commission for Health Improvement, 2000). An investigation should aim to establish the facts and a first priority should be the safety or protection of the resident from further abusive practice/s.

The framework shown in Figure 1 has been developed by the author as one way of helping managers in their decision-making and could be used alongside local authority adult protection polices and procedures.

The manager needs to make a written record of the incident as soon as possible after the allegation of abuse has been made. Consideration also needs to be given as to whether to seek advice and referral to an external agency. In some cases this may be a line manager, the local adult protection unit, social services contracts officer, CSCI and the police. The manager's decision to report may be informed by whether the abuse was an intentional or unintentional event. Although both intents would need intervention and action, depending on the nature of the act referral to an outside agency may not be necessary.

The credibility of the person reporting the abuse is a factor that will affect the judgement of the manager. It is important that the manager remains open minded and ascertains whether others can corroborate the incident. This study has shown that managers rate different types of abuse as more serious than others. However, it is important that any allegation of abuse warrants a minimum level of intervention.

Service user view

A first priority must be to find out the resident's feelings, views and level of distress about the matter. In some cases it may be appropriate to involve an advocate who can act independently. An allegation may be accompanied with extreme distress if a oneoff occurrence or with a declining state of depression as a result of long-term abuse. The manager also needs to take into account the mental state of the resident and his or her ability to understand and communicate the events that took place. 
Figure 1 Dealing with allegations of abuse: a framework for decision making by care home managers

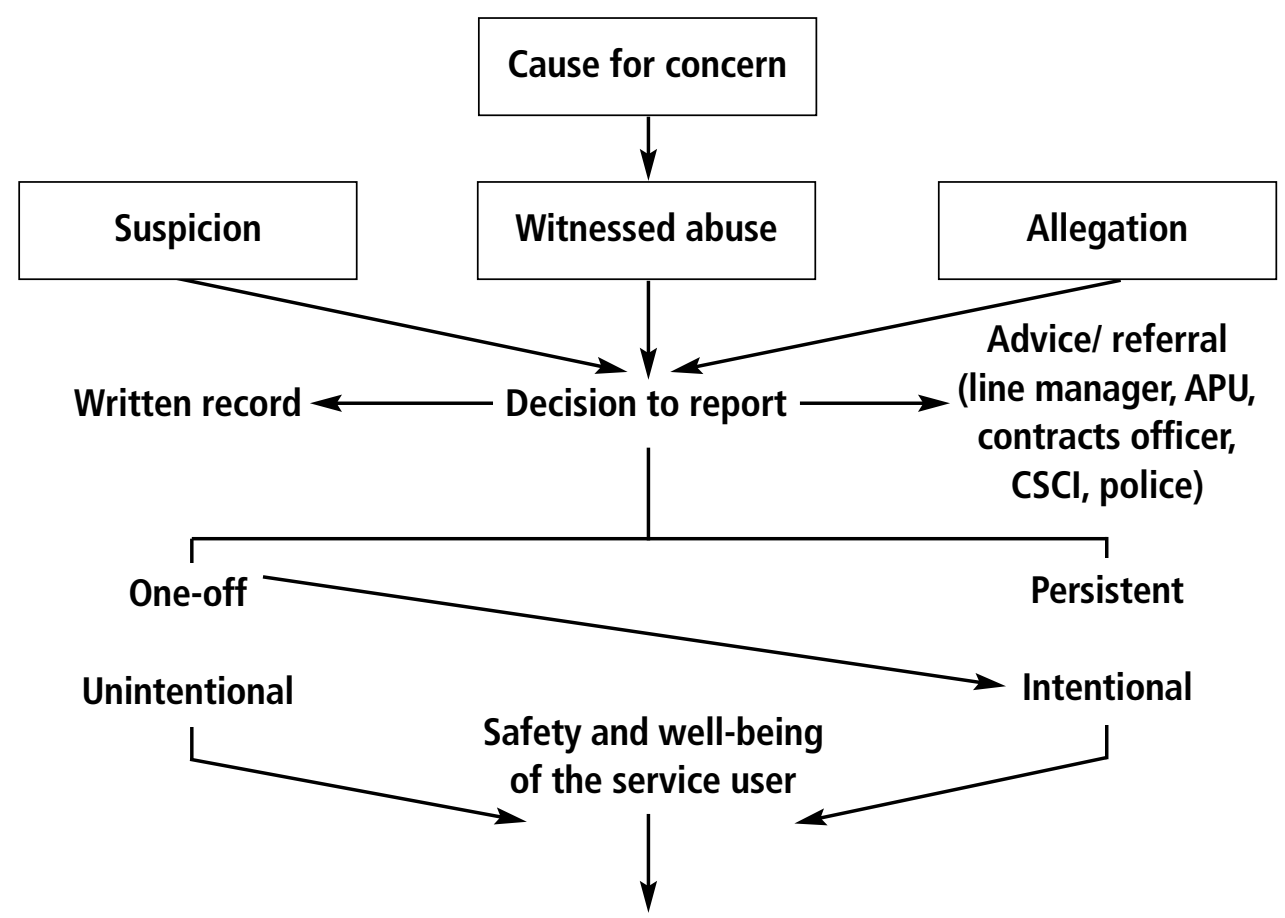

Service user view

Advocacy

Cultural and ethnic
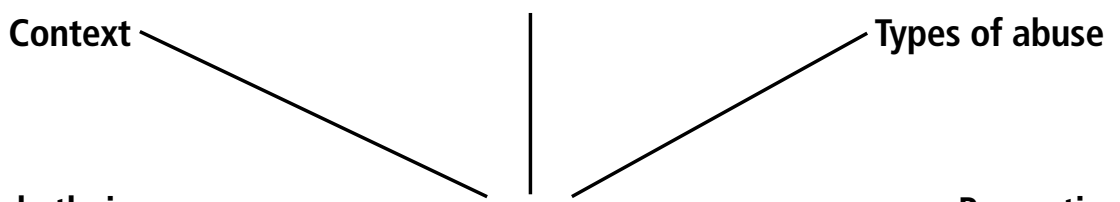

perspective

Perception of seriousness

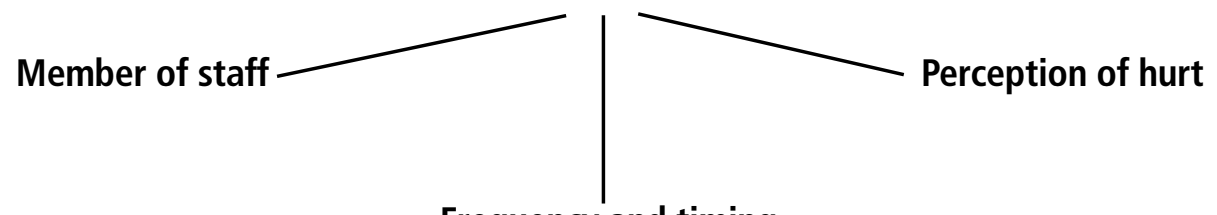

Frequency and timing

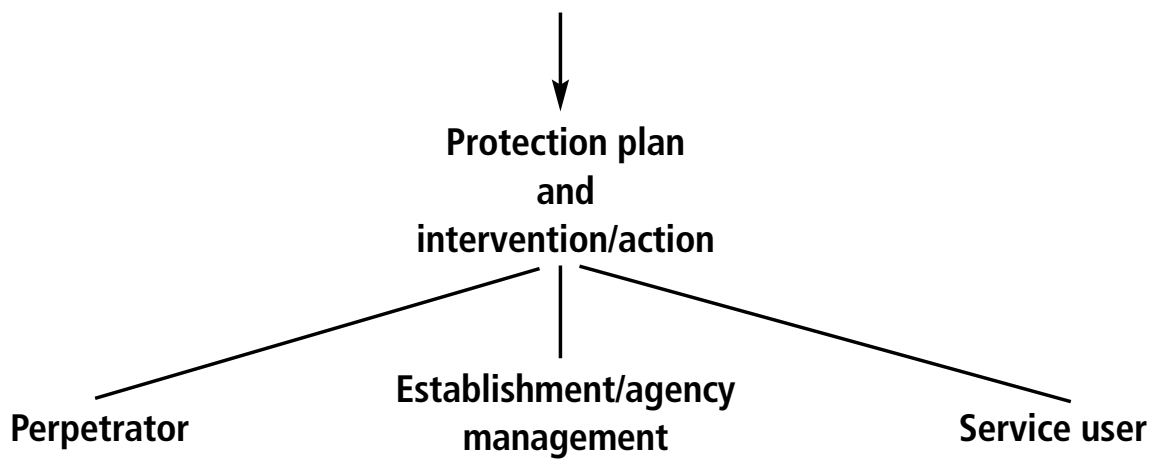




\section{Context}

The manager needs to consider the act or behaviour of the member of staff in relation to the environment and circumstances. Some abusive routines and regimes become established and acceptable practices by staff in certain environments. An example of this has been the use of restraints as a method of valuing safety above risk and individual liberty (Counsel and Care, 1992). If the staff member believes that an act is in the best interests of the resident then it can be difficult to shift this perception even when it is pointed out that this is an abusive practice. The frequency and timing of the incident may also be relevant. For example, allegations made at bedtime and about the same person may be significant. In contrast, some actions and behaviours would always be considered wrong regardless of circumstance. An example of this would be staff shouting back at residents.

The member of staff

If the alleged perpetrator is a member of staff then the manager should carry out a risk assessment that will take into account the past work history, his or her staff record and any concerns about work conduct. The manager may have different expectations of a qualified member of staff as opposed to an unqualified or newly appointed worker. Greater leeway might be given to the unqualified worker depending on the nature of the abuse. Other factors to consider would be staff and resident relationships, his/her personality, the current mental state and any known personal problems affecting performance at work.

\section{Perception of hurt}

There is a danger that a manager can underestimate the effects and impact of abusive practices and as a consequence these can be overlooked and perpetuated in daily routines. Hirst (2000) interviewed ten
Canadian nurses who articulated abuse as a perception of hurt to a resident. If the nurse believed that the resident had been offended then this was classed as abuse. It is important that judgements are based on objective criteria rather than subjective opinions to prevent both deliberate and unintentional acts of abuse.

\section{Protection plan and intervention}

If the abuse appears to be unintentional then it is important for the manager to identify and address the problem. Schon's (1983) model of reflection 'on-action' can help the manager to consider the factors in the workplace, the care practices and the staff member's personal situation that may have contributed to the poor practice. This model of reflection is a helpful process that enables learning from an event in order to prevent similar situations occurring in the future. Staff could also be interviewed to find out their level of awareness and understanding of abuse to ascertain whether their action had been through ignorance, bad habits or institutionalised practices.

If the incident had been a one-off and determined as an unintentional act such as speaking inappropriately to residents or restricting choices then the favoured interventions by managers were to reprimand the offending member of staff and to offer further training. In certain cases, managers also issued a written warning and a record of this was kept on the staff file.

Persistent, repeated and intentional abuse would lead to the suspension of the perpetrator and, pending a full investigation and the allegation proven, then the member of staff would be dismissed. There may be differences in disciplinary practices for care homes under local authority control. Guidance and advice should be sought from CSCI, APU, SS contracting officer, POVA and also the police if the abuse was a criminal offence. 


\section{Conclusions and recommendations}

Although there may be some differences in the legislation and policies governing the regulation and inspection of care homes in different countries, these findings are of interest to all concerned in the long-term care of older people. Registered owners and managers have a duty of care for the wellbeing and safety of their service users. However a manager's perceptions about the seriousness of the abuse, their prior experience of dealing with cases of abuse, confidence in approaching different agencies for advice, guidance and support and an adequate knowledge and understanding of adult protection policies affect the way that managers respond and deal with offending care staff. Managers need to feel confident that if they seek advice from outside agencies they will be supported to deal with perpetrators of abuse.

External pressures of regulation and inspection add to the responsibilities placed on managers to ensure that their homes provide a safe environment with well-trained caring staff. Managers also have to work hard to create a culture of openness by welcoming comments about any aspect of the care and responding sensitively and promptly, particularly to concerns raised by residents, staff and visitors alike. The responses by residents indicate the powerlessness of their position. Recognising that often the manager has to rely on others to report their concerns, individual and collective feedback should be actively sought as another way of providing opportunities for comment.

All managers need to be made fully aware of the requirement to report any allegations of abuse. This not only contributes to a collection of accurate statistics but also enables a consistency in the decision-making process that is open to scrutiny and provides access to appropriate advice, guidance and support. There may be a reluctance to report any allegations to CSCI and similarly to APU or SS for fear that this would damage the reputation of the home. In this study, only one manager stated that she would involve the police and this was in relation to an example of theft. Similarly, few managers mentioned referral to POVA. This implies that if managers deal with any cases of abuse in-house then it is unlikely that the names of perpetrators will be referred to POVA. Perpetrators will be able to move between homes and continue to abuse those in their care.

Managers were very mindful of employment legislation and the need to ensure that

the statutory three-step disciplinary procedure was correctly carried out to avoid costly employment tribunals and challenges by staff for wrongful dismissal (Citizens Advice Bureau, 2004). Managers indicated that they would seek advice from legal advisors to the home to offer some protection against litigation. Again, this is an area that could be covered as part of mandatory training for all registered managers.

Clearly any allegation of abuse can be distressing and challenging for all parties concerned. It is important that managers are supported and knowledgeable about the procedures in place to guide their actions. Unfortunately, those managers who had dealt with cases of abuse did provide more confident responses to the different case examples. Many local authorities do provide a free rolling programme of training for all social care staff. Sumner (2004) reported that only 21 per cent of partnerships, made up of a total of 140 local authorities in England, at the time of the survey in 2001, provided evidence of the resources to match training requirements. Mandatory training on adult protection could become part of the registration process for those responsible for 
managing and owning care homes. Regular regional and local training events for care home managers and others involved in the protection of older people living in care homes would be another positive step forward to foster better working relationships so that elder abuse can be tackled together in the spirit of No Secrets as a truly multi-agency approach to protecting vulnerable people.

\section{Author correspondence details}

\author{
Sheila Furness \\ Lecturer \\ Department of Social Sciences and \\ Humanities \\ University of Bradford \\ Bradford BD7 1DP
}

Tel: 01274234782

Email: s.furness@bradford.ac.uk

\section{References}

Baker AA (1975) Granny battering. Modern Geriatrics 8 20-4

Bennett G, Jenkins G \& Asif Z (2000) Listening is not enough: An analysis of calls to the Elder Abuse Response. Journal of Adult Protection 2 (1) 6-20.

Bennett G, Kingston P \& Penhale B (1997) The Dimensions of Abuse: Perspectives for practitioners. Basingstoke: Macmillan.

Burgner T, Russell P \& Whitehead S (1998) Independent Longcare Inquiry. Aylesbury: Buckinghamshire County Council.

Care Homes Regulations (2001) Regulation 37, Guidance on the Notification of Death, illness and Other Events. London: Stationery Office.

Citizens Advice Bureau (2004) What You Need to Know: Dealing with grievances, dismissal and disciplinary action at work. Citizens Advice Bureau. Available from: www.adviceguide.org.uk (accessed 20 October 2005) Commission for Health Improvement (2000) Investigation into: The North Lakeland Healthcare NHS Trust. Norwich: TSO.
Counsel and Care (1992) What if They Hurt Themselves. A discussion of the uses and abuses of restraint in residential and nursing homes for older people. London: Counsel and Care.

Daly JM \& Jogerst GJ (2005) Association of knowledge of adult protective services legislation with rates of reporting of abuse in Iowa nursing homes. Journal of American Directors Association 6 (2) 113-120.

Department of Health (1998) Modernising Social Services Promoting Independence, Improving Protection, Raising Standards. Cm 4169. London: HMSO.

Eastman M (Ed) (1984) Old Age Abuse: A new perspective. London: Chapman and Hall.

Department of Health (2000a) Care Standards Act. London: Stationery Office.

Department of Health (2000b) No Secrets: Guidance on developing and implementing multi-agency policies and procedures to protect vulnerable adults from abuse. London: Stationery Office.

Department of Health (2003) Care Homes for Older People National Minimum Standards Care Homes Regulations (3rd edition). London: Stationery Office.

Department of Health (2005) Action on Elder Abuse. Report on the project to establish a monitoring and reporting process for adult protection referrals made in accordance with 'No Secrets'. Available from: www.dh.gov.uk (accessed 8 November 2005).

Gilleard C (1994) Physical abuse in homes and hospitals. In: Eastman M (Ed) Old Age Abuse: A new perspective. London: Chapman and Hall.

Hirst SP (2002) Defining resident abuse within the culture of long-term care institutions. Clinical Nursing Research 11 (3) 267-284.

House of Commons Health Select Committee (2004) Elder Abuse. Second report of session 2003-4 Vol 1 Report, together with formal minutes. London: Stationery Office.

Kingston P \& Brammer A (Eds) (1997) Caring in Trouble. Basingstoke: Macmillan

Manthorpe J (Ed) (2000) The Great Taboo: sexual abuse of older people Working Paper 5. London: Action on Elder Abuse.

Manthorpe J, Perkins N, Penhale B, Pinkney L \& Kingston P (2005) Select questions: considering the issues raised by a Parliamentary Select Committee Inquiry into elder abuse. Journal of Adult Protection 7 (3) 19-32.

Mathew D, Brown H, Kingston P, McCreadie C \& Askham J (2002) The response to No Secrets. Journal of Adult Protection 4 (1) 4-14.

National Care Standards Commission (2003) The Business Plan 2002-3. London: Stationery Office.

O'Kell S (2002) The independent care homes sector Implications of staff shortages on service delivery. Joseph Rowntree Foundation. Available from: www.jrf.org.uk/bookshops/ebooks/1842631373.pdf (accessed 31 October 2005). 
Recognising and addressing elder abuse in care homes: views from residents and managers

Parker J (2001) Seeking effective approaches to elder abuse in institutional settings. Journal of Adult Protection 3 (3) 21-29.

Pillemer K \& Moore DW (1989) Abuse of patients in nursing homes: Findings from a survey of staff. Gerontologist 29 314-320.

Richardson B, Kitchen G \& Livingston G (2002) The effect of education on knowledge and management of elder abuse: a randomised controlled trial. Ageing and Society 31 331-341.

Schon D (1983) The Reflective Practitioner. New York: Basic Books.
Sumner K (2004) Social Services Progress in Implementing 'No Secrets'- an analysis of codes of practice. Journal of Adult Protection 6 (1) 4-11.

Stevens M \& Manthorpe J (2005) POVA referrals-the first 100: Analysis of the first 100 referrals to the POVA list. Kings College London/University of London: Social Care Workforce Research Unit.

Taylor K \& Dodd K (2003) Knowledge and attitudes of staff towards adult protection. Journal of Adult Protection 5 (4) 26-32. 


\section{Appendix}

Part of the questionnaire used for the interview with each homeowner/ manager

Ask permission to carry out and record the interview.

How long have you owned/managed the home?

Can you tell me a little about your background/qualifications and relevant work experiences prior to becoming an owner/manager.

How many residents are you registered to take?

How many residents are there at the moment?

\section{Adult protection}

What do you understand by abuse?

Unfortunately some homes do not provide adequate care and look after residents properly.

What are the sort of things that you would find unacceptable?

How would you score the following situations as a percentage?

(0\% not at all serious to $100 \%$ extremely serious)

A member of staff slapping a resident

If you saw this happen, what would you do?

What should happen to the member of staff?

A member of staff stealing money from a resident's purse

If this was reported to you, what would you do?

What should happen to the member of staff?

A member of staff roughly pulling a resident up from a chair

If you saw this happen what would you do?

What should happen to the member of staff?

A member of staff forgetting and leaving a resident in the toilet for 20 minutes

If this was reported to you, what would you do?

What should happen to the member of staff?

A member of staff ridiculing a resident who has dementia

If you saw this happen what would you do?

What should happen to the member of staff?

A member of staff telling a resident if she does not stop moaning she will have to move to another home

If you heard this, what would you do?

What should happen to the member of staff?

Can you think of any other situations which would concern you? 
Have you ever witnessed any of the above? If so, which ones and what happened?

In your experience, have you ever had to deal with any abusive situation? Can you give me any examples and the action you took?

What are the factors which would influence you about what action to take?

Why do you think abuse occurs?

Who do you think may be most at risk of abuse?

Who would you go to for advice and support if you suspected a member of staff abusing residents?

Have you got an adult protection policy?

How does it work?

How useful or effective do you think this is?

What can be done to ensure that older people in care homes are being properly cared for?

Any other comments you would like to make?

\section{Part of the questionnaire used for the interview with each resident}

Ask permission to carry out and record the interview.

How long have you lived at this home?

Can you tell me a little about how you came to live here at this home?

\section{Unacceptable practices}

Unfortunately not all care homes provide good care and look after residents properly. What are the sort of things that would concern you or that you would find unacceptable?

How would you score the following situations as a percentage?

( $0 \%$ not at all serious to $100 \%$ extremely serious)

A member of staff swearing at a resident

If you heard this happen, what would you do?

What do you think should happen to the member of staff?

A member of staff stealing money from a resident's purse.

If you saw this happen what would you do?

What do you think should happen to the member of staff?

A member of staff roughly pulling a resident up from a chair

If you saw this happen what would you do?

What do you think should happen to the member of staff?

A member of staff forgetting and leaving a resident in the toilet for 20 minutes

If you saw this happen what would you do? 
What do you think should happen to the member of staff?

A member of staff making fun of a resident who has dementia

If you saw this happen what would you do?

What do you think should happen to the member of staff?

Can you think of any other situations which would concern you?

What would you describe as abuse?

Have you ever witnessed any of the above? If so, which ones and what happened?

\section{Taking Action}

If you witnessed any of the above situations who would you most likely speak to first about your concerns.

Using the scale 0 not at all to 10 very likely to tell, how likely is it that you would tell the following people:

The homeowner

The manager

A member of staff

A relative

A fellow resident

A visitor to the home

An inspector

Anyone else

How seriously do you think that your views would be taken?

0 not at all to 10 very seriously

What do you think could be done to ensure that all residents in care homes are being properly cared for?

Any other comments you would like to make? 